\title{
SCREENING OF AZADIRACHTA INDICA SEED OIL AGAINST SAP-STAIN AND MOULD FUNGI IN IMPORTED TECTONA GRANDIS AND SOUTHERN YELLOW PINE WOOD THROUGH FUMIGATION
}

\author{
Ganguly S*, Tripathi S, Tiwari P, Sumi A \& Kanyal R \\ Wood Preservation Discipline, Forest Products Division, Forest Research Institute, Dehradun - 248006, India \\ *sauradipta.ganguly@gmail.com
}

Submitted January 2019; accepted November 2019

\begin{abstract}
Discoloration due to the attack of sap-stain and mould fungi has been known to reduce the value and aesthetics of timber products and render them unfit for specific uses where the appearance plays a crucial role in determining its importance. The efficacy of seed oil from Azadirachta indica as a fumigant was tested against sap-stain and mould fungi in imported Tectona grandis and southern yellow pine wood at temperature $25 \pm 2{ }^{\circ} \mathrm{C}$ and relative humidity $75 \pm 5 \%$. It was observed that the neem seed oil was effective in inhibiting the growth of sap-stain and mould fungi cultured in potato-dextrose agar (PDA) medium. The inhibition in the growth of mould and sap-stain fungi on fumigated wood reveals the potential of neem seed oil as an eco friendly preservative in lieu of the existing toxic chemicals.
\end{abstract}

Keywords: Azadirachta indica seed oil, mould, sap-stain, Tectona grandis, southern yellow pine

\section{INTRODUCTION}

Service life of wood depends primarily on the species, the amount of sap present within, the end use and the environmental conditions to which it is exposed. The term durability of wood defines its natural resistance against wood decaying fungi and insects (Kumar and Dev 1993). It varies widely from tree to tree and also within trees. Concentrations and nature of extractives present, that have termicidal and fungicidal properties, play a pivotal role in determining the natural resistance of wood. The concentration within the tree varies from pith to periphery, and further varies with seasons and age of the tree (Syofuna et al. 2012).

Sap-stain causes discolouration of sapwood due to pigmented hyphae of several taxonomic fungi groups (Thwaites et al. 2005). In addition, there are some wood species that are more likely to be affected by non-biological and chemical stains which reduce the value of the finished products (Morrell et al. 2002). Comparative tests show that sap-stained wood decays somewhat more rapidly than non-stained wood, which can be attributed to the fact that sap-stained wood absorbs more moisture and creates a favourable condition for microbial outgrowth (Findlay et al. 1939). Discoloration often lowers the cost of commodities and results in loss of revenues. Mould is also a kind of fungal damage to wood, consisting mainly of unsightly surface growths of fungi, and is sometimes troublesome on green lumber, in particular, and other wood products. The common mould fungi belong to Ascomycetes and Deuteromycetes (fungi imperfecti) (Scheffer and Lindgren 1940). Aspergilus sp. and Penicilium sp. are the common mould fungi found on most of the tropical hardwoods (Cartwright and Flndlay 1948). Moulds do not discolour wood as deeply as does sap-stain fungi, however, the discoloration may penetrate deep into the wood making it visible even after the stock is surfaced, particulary in hardwoods. Both mould and sapstain fungi are essentially limited to sapwood, and their effect on wood strength and absorptivity are somewhat alike (Scbeffer 1958).

Shortage in supply of indigenous, durable species of timber has resulted in timber import worldwide, especially in India, and prompted the use of imported timber that are highly susceptible to attack by wood deteriorating biological agents 
in Indian climatic conditions. The inherent durability of these species under different climatic conditions is unknown, and thus must be determined to utilise them effectively. Studies on natural resistance of wood against biological damage are therefore of prime importance (Sundararaj et al. 2015).

India, over the years has become a net importer of timber. In 2015, the Indian market is said to have imported an estimated 18.01 million cum of timber, pulpwood and allied products worth USD6,701.3 million, which included wood logs, panel and plywood, pulpwood, paper, furniture and other wooden products (Shrivastava and Saxena 2017).

In ecology and forestry, yellow pine refers to a number of conifer species which tend to grow in similar plant communities and yield similar strong wood. In southern United States, yellow pine refers to longleaf pine, shortleaf pine, slash pine or loblolly pine. In the United Kingdom, yellow pine refers to eastern white pine or scots pine. They have the highest densities (between 36 to $42 \mathrm{lbs} \mathrm{ft}^{-3}$ average dried weight), very abrupt earlywood to latewood transitions, and very unevenly grained. All of the species in this grouping are essentially indistinguishable from one another, even under microscopic examination. The four major species of southern yellow pine are: shortleaf pine (Pinus echinata), slash pine (Pinus elliotti) longleaf pine (Pinus palustris) and loblolly pine (Pinus taeda) (Meier 2019).

Besides many soft wood species like spruce, pine, fir, etc., few hard wood species, such as Tectona grandis, are also being imported as a choice of timber for different end uses. Tectona grandis is a native to India, Sri Lanka, Indonesia, Myanmar, northern Thailand, and north-western Laos. Tectona grandis is found in a variety of habitats and climatic conditions from arid areas with only $500 \mathrm{~mm}$ of rain per year to very moist forests with up to $5,000 \mathrm{~mm}$ of rain per year (Meier 2019).

Tectona grandis of Indian origin is durable in nature, and hence is being used as the reference species (IS 401: 2001). Recent studies revealed that imported T. grandis has lower durability in Indian climatic condition, hence preservation is needed to achieve optimum life span.

In recent times the wood and wood processing industries across the country have been facing several hurdles pertaining to wood protection practices. Fumigation is one of the widely used protection methods prevailing across the globe while the woody material is in transit. It is the process in which a chemical (fumigant), at a given pressure and temperature, in gaseous state, is lethal to selected pests trying to invade the substrate (Monro 1980). Fumigants are a new class of chemical formulation for wood protection through surface adsorptions. Methyl bromide is commonly and widely used for fumigation across the globe. It is one of the most preferred fumigants because of its ability to penetrate quickly and deeply into porous materials at normal atmospheric pressure (Bond 1984). However, methyl bromide is known to deplete the ozone layer and is listed in Schedule 1, in the list of ozone depleting substances. Further, it has also been reported for mammalian toxicity (Krameash 2015). Hence, an International Plant Protection Convention (IPPC) recommendation on the replacement or reduction of the use of methyl bromide as a phytosanitary measure has been adopted (CPM 2008). In light of the above, alternative treatments that are more environmentally friendly are being pursued (Pant 2010, Pant and Tripathi 2010, 2011, Rao 1990).

Neem (Azadirachta indica) plants contain several thousands of chemical constituents. Leaves and neem seed oil of A. indica has been found to have antibacterial, antifungal and medicinal properties (Mahmoud et al. 2011). Neem seed oil (NSo) is considered to be a storehouse of various active compounds responsible for medicinal, insecticidal and pesticidal property (Tewari 1992, Chaudhary et al. 2017). Besides this, it has exhibited its potential as a wood preservative (Dhyani 2008). Research reports have shown the presence of active ingredients in all botanical parts of the neem tree, however largely concentrated in the seed kernels. Neem seeds contain more than 100 active compounds which are called triterpenoids or limonoids, including azadirachtin which is the most important of bio-pesticides and insecticides (Djibril et al. 2015). A group of limonoids/triterpenoids including azadirachtin, nimbin, nimbidin, salanin, salannol, quercetin, gedunin have been reported, and out of these, the most active and well studied compound is azadirachtin $\left(\mathrm{C}_{35} \mathrm{H}_{44} \mathrm{O}_{16}\right)$ (Mondal and Mondal 2012).

The NSo has been found to be highly efficacious against wood decaying fungi (brown 
and white rot) in laboratory and against wood destroying termites, both in laboratory and mound, at very a low concentration, and its potential as an eco-friendly preservative has been established (Dhyani 2008, Dua et al. 2016).

Earlier studies conducted by Pant and Tripathi (2011) revealed efficacy data for wood destroying insect, Lyctus africanas. However, a preliminary screening of efficacy for sap-stain and moulds on imported timber has not been reported.

In view of the above, the efficacy of neem oil as a fumigant was assessed against fungal spore suspension and mould on southern yellow pine (SYP) and T. grandis.

\section{MATERIALS AND METHODS}

To study the efficacy of neem seed oil as a fumigant against test sap-stain and mould fungi, in different concentrations on imported $T$. grandis and SYP, the experiments were carried out in the laboratory of Wood Preservation Discipline, Forest Research Institute, Dehradun (3031' N, 7803' E).

Untreated sawn planks of test species, $T$. grandis from Ghana and SYP from South America, were imported through Kandla Port, Gujarat, India. Bombax ceiba, procured from Range Office, Forest Research Institute, Dehradun, India $\left(30^{\circ} 31^{\prime} \mathrm{N}, 78^{\circ} 03^{\prime} \mathrm{E}\right)$, served as control (untreated) (IS 4833 : 1993).

Azadirachta indica seed oil, extracted through cold pressing, commercially available in open market, was procured for test. A quantity of $1 \mathrm{ml}(0.9 \mathrm{~g}), 2 \mathrm{ml}(1.8 \mathrm{~g})$ and $3 \mathrm{ml}(2.7 \mathrm{~g})$ NSo, dissolved in 1-2 $\mathrm{ml}$ of petroleum ether $\left(60-80{ }^{\circ} \mathrm{C}\right)$, was used for fumigation.

\section{Test fungi used for the experiment}

Pure cultures of fungi (Alternaria alternata) and green mould (Penicillium sp.) were isolated from Rhododendron arboreum.

Black mould (Stachybotrys sp.), national type culture collection No.1175, was procured from Forest Pathology Division, Forest Research Institute, Dehradun, India.

\section{Preparation of culture medium}

A nutrient medium of potato-dextrose agar (PDA) in distilled water was prepared by dissolving $39 \mathrm{~g}$ of PDA in $1000 \mathrm{ml}$ in a flask and autoclaved for 20 minutes at $120^{\circ} \mathrm{C}$ temperature and 15 psi pressure. The media was kept in a laminar flow for 15 minutes and poured into sterilised Petri plates of $9 \mathrm{~cm}$ diameter (Datar 1995).

\section{Preparation of conidial suspension}

To prepare the conidial suspension, $10 \mathrm{ml}$ of sterile water was poured into each Petri plate and the surface of the PDA medium containing mycelial growth was scrapped with an inoculation needle and collected in a beaker. The volume was made up to $500 \mathrm{ml}$ by adding sterile distilled water and mixed

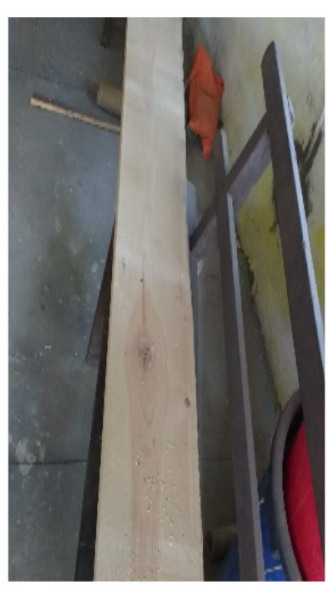

A

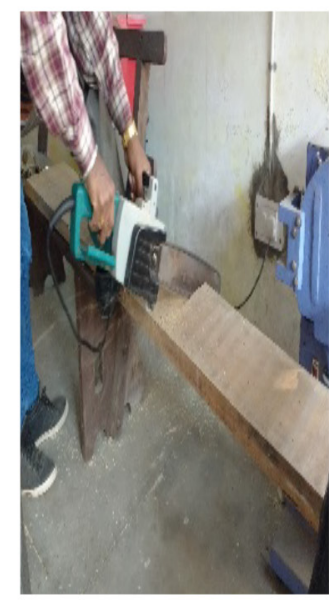

B
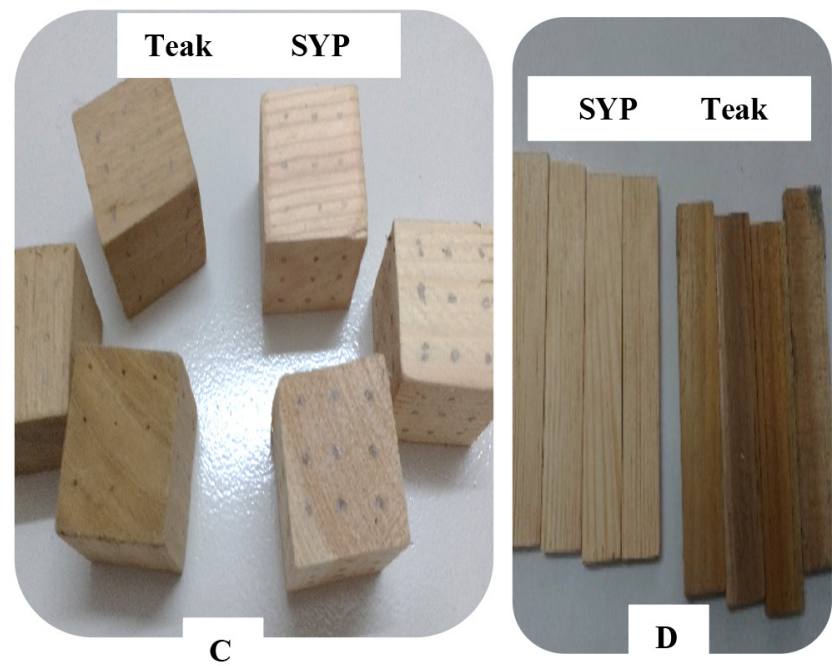

Plate 1 Preparation of test specimens a) procured southern yellow pine planks b) sawing of Tectona grandis planks c) marking of block samples d) veneer specimen of southern yellow pine (SYP) and teak 
uniformly using a magnetic stirrer for 10 minutes, and stored in cold condition at $4{ }^{\circ} \mathrm{C}$. The conidial $\mathrm{cfu} \mathrm{ml} \mathrm{l}^{-1}$ was $2 * 10^{6}$.

\section{Efficacy evaluation of neem seed oil in Petri plate block bioassay}

\section{Petri plate bioassay}

Petri dishes with PDA medium were placed in desiccators connected with the fumigation assembly (Plate 2). The fumigant, NSo, was placed in a conical flask and heated. Before heating, partial vacuum $(60 \mathrm{~mm} \mathrm{Hg})$ was created for 5-10 minutes, replacing air by opening stop cock 2, while stop cock 1 was kept closed during this period. Then, the fumigant was heated and the fumes were allowed to pass into a desiccator through an attached tube by opening stop cock 1 , while stop cock 2 was closed. Different concentrations of NSo, as described above, were used for the study. The heating process was carried out for one hour and the Petri plates were left in the desiccator for 24 hours (Pant 2010).

Under aseptic conditions of laminar flow, A. altrenata, Stachybotrys sp. and Penicillium sp., were each inoculated on the 6 fumigated PDA plates, as described in section 2.2. Six controls were maintained without fumigation. The plates were incubated at $25 \pm 2{ }^{\circ} \mathrm{C}$ and $75 \pm 5 \%$ RH for 12-14 days to allow growth. The results were recorded after 15 days in percentage of surface coverage by the test fungi over the agar media (Kapse 1996, Wedge et al. 2000, Pant 2010).

Grading of surface coverage of the test fungi on PDA medium was carried out:

\begin{tabular}{lc}
\hline Growth type & $\begin{array}{c}\text { Surface coverage of mycelium on } \\
\text { the medium }(\%)\end{array}$ \\
\hline None & 0 \\
Sporadic & $0-5$ \\
Little & $6-25$ \\
Moderate & $26-50$ \\
Considerable & $51-75$ \\
Complete & 75 \\
\hline
\end{tabular}

\section{Block and veneer bioassay}

The fumigation assembly was set up as depicted in Plate 2. For each concentration and control, ten replicates were used. For fumigation, the test blocks were kept inside a desiccator, connected to a vacuum pump. A partial vacuum $(60 \mathrm{~mm} \mathrm{Hg})$ was created inside the desiccator for 5 minutes to expel air.

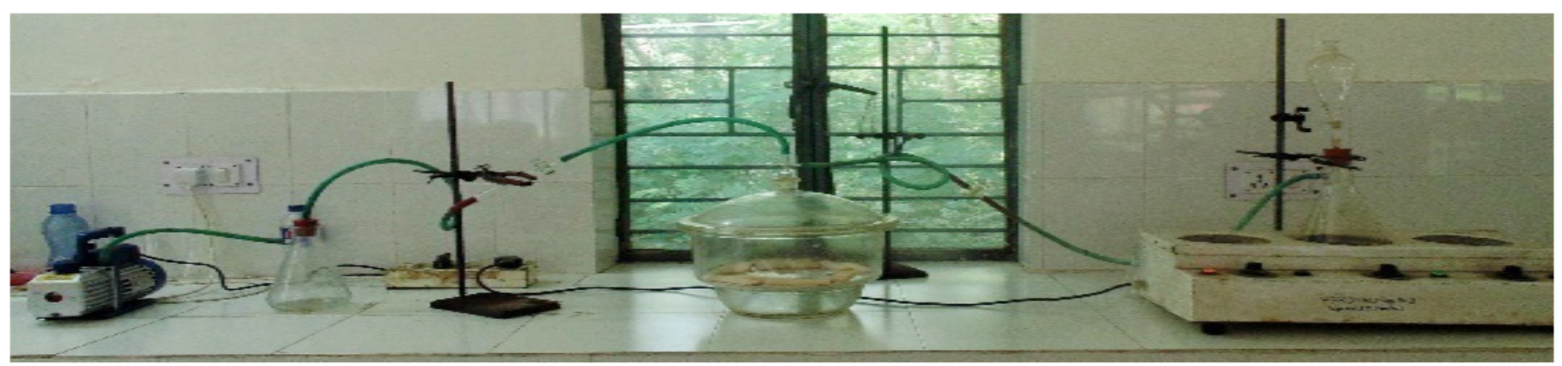

Fumigation assembly

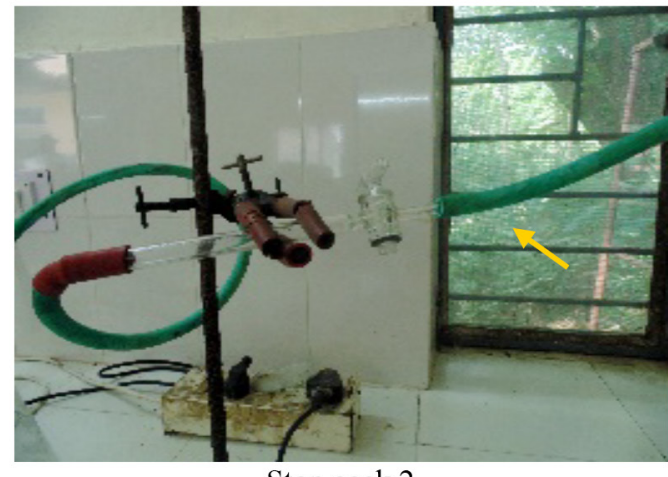

Stop cock 2

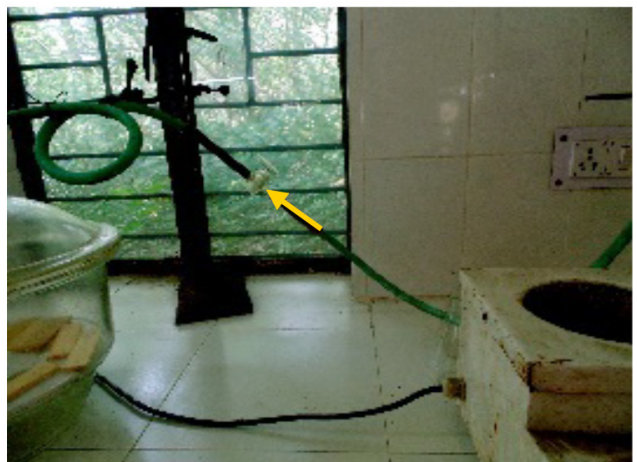

Stop cock 1

Plate 2 Fumigation assembly 


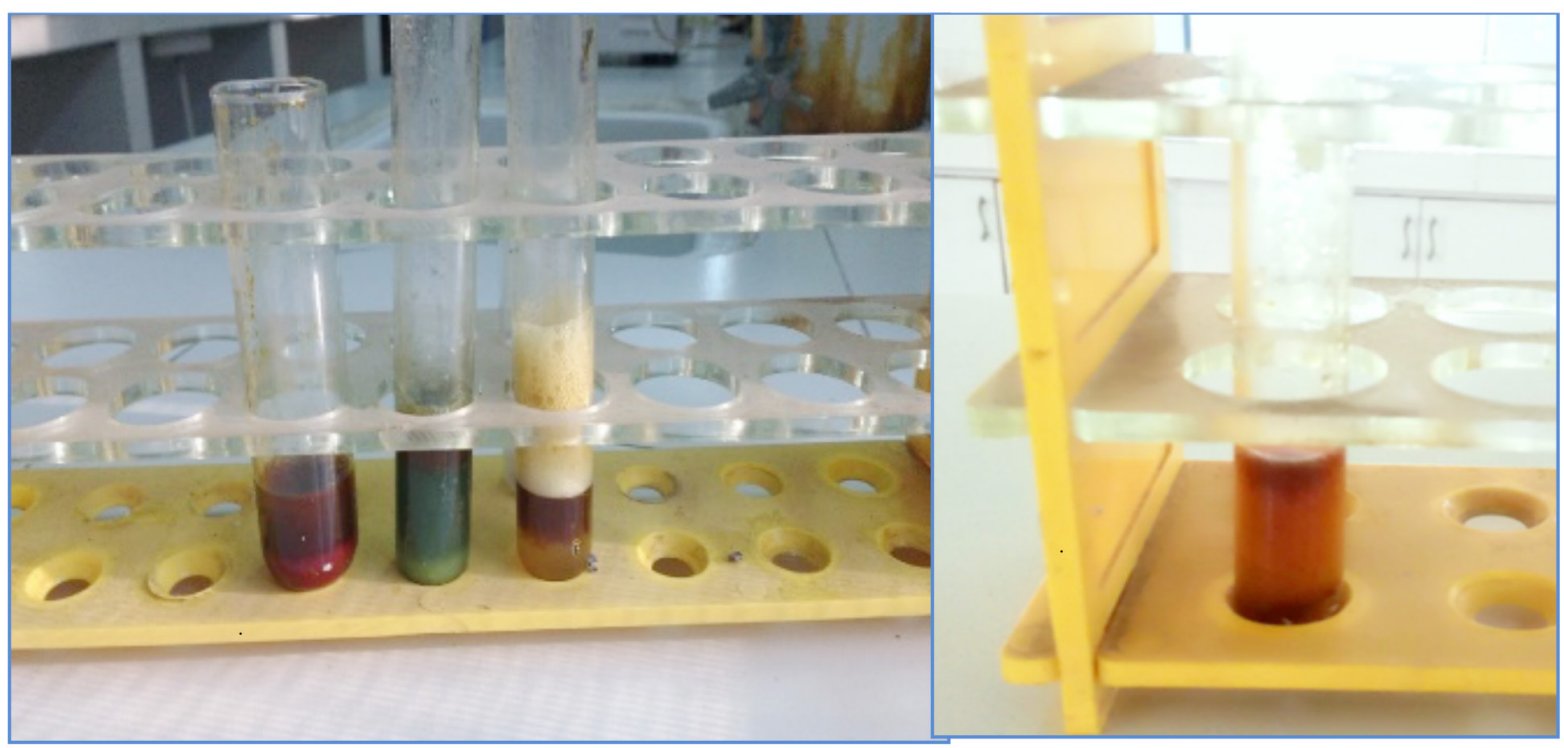

Plate 3 Qualitative analysis of the presence of major functional groups in neem seed oil

A known amount of NSo fumigant was then heated in a conical flask on a hot plate, and connected to the desiccator with the help of a rubber tube for free flow of fumigant/volatiles from flask to desiccator.

Test blocks and veneers were fumigated for 4 weeks, after which results were recorded. The test boxes were incubated during this process, as mentioned in section 2.5.

\section{Preparation of wood specimens}

\section{Test blocks}

Planks were converted into test blocks of size 3.5 $\times 3.5 \times 3.5 \mathrm{~cm}$ (Plate 4$)$. On each side of the test blocks, nine holes were made approximately 0.7 $\mathrm{cm}$ apart from the edge and $1 \mathrm{~cm}$ apart from each other. The test blocks were then kept in a desiccator using calcium chloride salt as drying agent.

\section{Test veneers}

Planks of B. ceiba, T. grandis and SYP were converted into billets of size $100 \times 2.5 \times 2 \mathrm{~cm}$. The billets were converted into veneers of size $10 \times 2.5 \times 0.6 \mathrm{~cm}$ (Plate $1 \mathrm{~A}-\mathrm{D})$.

Details of the treatments are as below:

$$
\mathrm{TT}_{1}, \mathrm{TT}_{2}, \mathrm{TT}_{3}, \mathrm{SPT}_{1,} \mathrm{SPT}_{2}, \mathrm{SPT}_{3}, \mathrm{TC} \text { and } \mathrm{SPC}
$$

where, $\mathrm{T}=T$. grandis, $\mathrm{SP}=\mathrm{SYP}, \mathrm{T}_{1}=1 \mathrm{ml} \mathrm{NSo}$ $(0.9 \mathrm{~g}), \mathrm{T}_{2}=2 \mathrm{ml}$ NSo $(1.8 \mathrm{~g}), \mathrm{T}_{3}=3 \mathrm{ml}$ NSo $(2.7$ g), $\mathrm{C}_{1}=$ control of test species $\mathrm{SYP} / T$. grandis, $\mathrm{C}_{2}$
$=$ control of $B$. ceiba; total specimens prepared $=180$; Petri plate bioassay $=48$ Petri plates; moisture content was determined on oven-dry (OD) basis as per Bureau of Indian Standards (BIS) (IS 11215: 1991) prior to the experiment.

\section{Preparation of test box}

Transparent plastic boxes were sterilised using spirit at $120^{\circ} \mathrm{C}$ and 15 psi pressure before using. At the bottom of these boxes, sterilised pads of moistened Whatman's filter papers were placed to maintain higher humidity. Air bubbles trapped under the paper were pressed out and thin sterilised bamboo sticks were placed on the top.

\section{Fumigation of test blocks}

A total of 10 test specimens of SYP and T. grandis were placed in a desiccator and fumigated as described in section 2.2. The heating process was carried out for one hour for the blocks and 15 minutes for the veneers. Test blocks were placed in the desiccator for $24 \mathrm{~h}$ and veneers for $0.5 \mathrm{~h}$ before inoculation (Pant 2010).

\section{Inoculation of test blocks}

The treated blocks (test blocks and veneers) along with the controls were placed on bamboo sticks. Under the aseptic condition of laminar flow, the blocks were frequently sprayed with fungal conidial suspension. At every interval of three days, the inoculum suspension was sprayed 

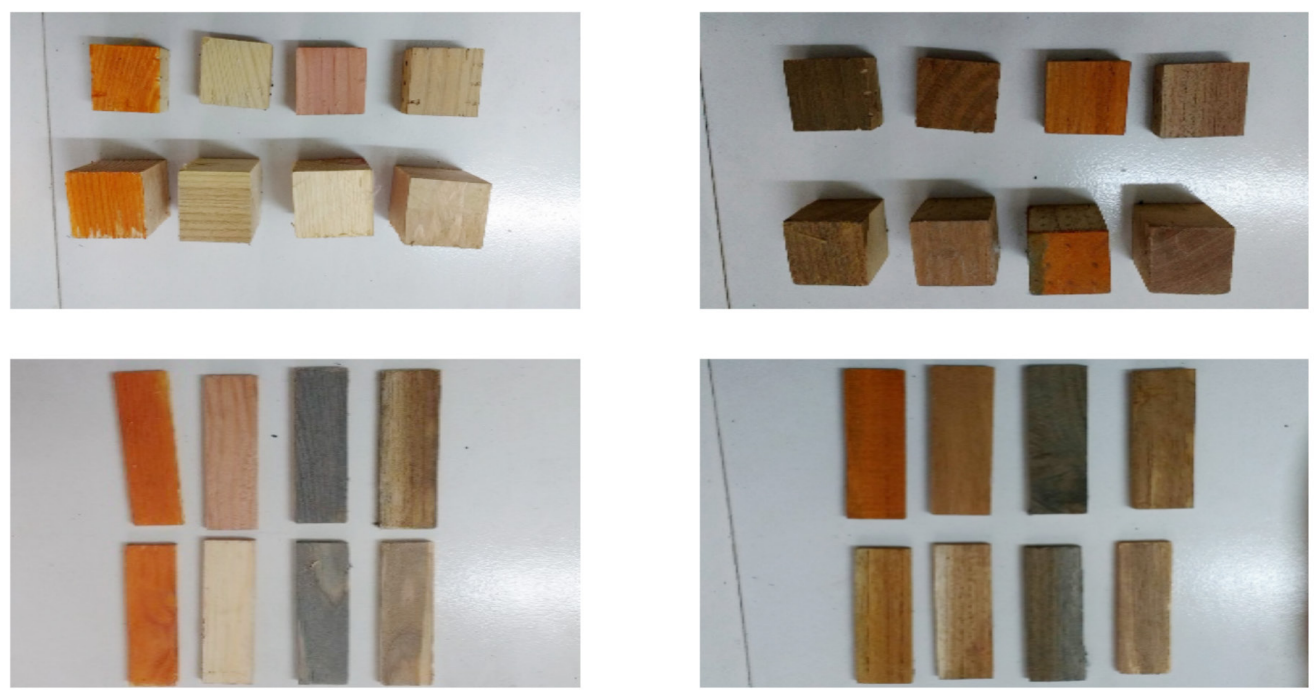

Plate 4 Qualitative analysis for the presence of major functional group in untreated and fumigated Teak veneers

(1 $\mathrm{ml}$ on each specimen exterior surface) until the surface of the untreated specimen was overgrown with sporulating fungi.

The boxes were incubated at $25 \pm 2{ }^{\circ} \mathrm{C}$ and 75 $\pm 5 \% \mathrm{RH}$ for 4 weeks. Moisture was maintained inside the box during incubation by wetting with sterile distilled water. After 4 weeks, visual observation and grading was carried out (ASTM D4445-09 2009):

\begin{tabular}{lc}
\hline \multicolumn{1}{c}{ Infestation } & Grading \\
\hline No stain or fungal growth & 0 \\
$\begin{array}{l}\text { Stain or fungal growth covering less than 20\% } \\
\text { of upper surface }\end{array}$ & 1
\end{tabular}

Stain or fungal growth covering $20-40 \%$ of 2 upper surface

Stain or fungal growth covering $40-60 \%$ of 3 upper surface

Stain or fungal growth covering $60-80 \%$ of 4 upper surface

Stain or fungal growth covering more than $80 \% \quad 5$ of upper surface

\section{Qualitative analysis of major functional groups present in the extractive}

The NSo, 4-5 drops, dissolved in $4 \mathrm{~mL}$ of petroleum ether $\left(60-80{ }^{\circ} \mathrm{C}\right)$ was subjected to qualitative analysis for the presence of major functional groups (Vogel 1978, Stahl 1969) (Plate 3).

\section{Test for phenol}

Ferric chloride $\left(\mathrm{FeCl}_{3}\right)$ test: $3-4$ drops of aqueous or alcoholic solution of ferric chloride (AR grade) was added to NSo, and the appearance of a characteristic green colour indicated the presence of phenol (Vogel 1978, Stahl 1969).

\section{Test for flavonoid}

A small amount, 3-4 drops of NSo, was mixed with $2 \mathrm{~mL}$ of ethanol. Magnesium turnings and 5 drops of $2 \mathrm{~N} \mathrm{HCl}$ were added to the above solution. The appearance of red colour indicated the presence of flavonoid (Vogel 1978, Stahl 1969).

\section{Test for alkaloid}

The test was performed on NSo (4-5 drops) as reported by Vogel 1978 and Stahl 1969.

\section{Test for terpenoid}

Liberman Burchard test was conducted on NSo as reported by Vogel 1978 and Stahl 1969.

\section{RESULTS AND DISCUSSIONS}

The natural durability of any wood provides inherent resistance to wood-destroying agents. Natural durability can vary widely depending on the age of the tree, geographical origin of the tree species, growing conditions and extractives (McDonald and Donaldson 2001). Theses extractives may be phenols, alkaloids, terpenes and terpenoids which are toxic to wood infesting bacteria, fungi and insects. Generally, heart wood contains higher levels of extractives than 
sapwood, hence more resistant. In imported timber, however, it is difficult to assess the quantity of heart and sap wood as it is received in sawn form. Therefore it is interesting to evaluate the presence and impact of major functional groups in NSo and the wood itself.

Colour development with detecting agents revealed their presence. Qualitative analysis revealed an appreciable amount of phenol and considerable amounts of flavonoid, alkaloid and terpenoid in NSo. Intense colour development in treated and untreated wood specimens revealed the presence of phenol in the wood specimens. Therefore, wood it is expected to have natural resistence. Similarly, alkaloids were present in considerable amounts in NSo, while untreated wood specimens did not exhibit the presence of alkaloids (Table 1).
The growth type grading of fungal mycelium was carried out as described in section 2.2, and the results are shown in Table 2. Mould showed sporadic growth covering $2 \%$ area of the PDA medium upon receiving $\mathrm{T}_{1}$, while there was no visual mould growth on PDA medium that received treatments $T_{2}$ and $T_{3}$. The surface coverage of the mycelium on control PDA medium in Petri plates was moderate with percentage coverage of $40 \%$ for mould. Thus, it can be deduced that the efficacy of NSo increased significantly $(\mathrm{p} \leq 0.05)$ with increasing concentrations, and inhbited fungal growth completely at higher concentrations.

All three concentrations of NSo was equally effective against sap-stain fungi in PDA medium as no visual fungal growth was seen in either of the treatments. However, the control specimens

Table 1 Qualitative test of NSo and wood specimens

\begin{tabular}{ccccc}
\hline Slide No. & $\begin{array}{c}\text { Qualitative } \\
\text { analysis }\end{array}$ & $\begin{array}{c}\text { Colour developed in } \\
\text { NSo }\end{array}$ & $\begin{array}{c}\text { Colour developed in } \\
\text { untreated wood specimens }\end{array}$ & $\begin{array}{c}\text { Colour developed in } \\
\text { treated wood specimens }\end{array}$ \\
\hline 1 & Phenol & ++ & +++ & ++++ \\
2 & Flavonoid & ++ & ++ & +++ \\
3 & Alkaloid & ++ & - & + \\
4 & Terpenoid & ++ & +++ & +++ \\
\hline
\end{tabular}

Color development by detecting reagents: absence or presence of functional groups tested is indicated as absence $(-)$, slight presence $(+)$, considerable $(++)$, appreciable $(+++)$ and intense $(++++)$

Table 2 Grading of surface coverage of mould and sap-stain on PDA medium

\begin{tabular}{ccccccc}
\hline Treatments & \multicolumn{5}{c}{ Mould } & \multicolumn{3}{c}{ Sap-stain } \\
\cline { 2 - 6 } & $\begin{array}{c}\text { Infestation } \\
\text { (approx.) }(\%)\end{array}$ & $\begin{array}{c}\text { Grading of } \\
\text { surface coverage }\end{array}$ & Growth type & $\begin{array}{c}\text { Infestation } \\
\text { (approx.) }(\%)\end{array}$ & $\begin{array}{c}\text { Grading of } \\
\text { surface coverage }\end{array}$ & Growth type \\
\hline Control & 40 & Moderate & Moderate & 95 & Complete & Complete \\
$\mathrm{T}_{1}$ & 2 & Sporadic & Sporadic & 0 & None & None \\
$\mathrm{T}_{2}$ & 0 & None & None & 0 & None & None \\
$\mathrm{T}_{3}$ & 0 & None & None & 0 & None & None \\
\hline
\end{tabular}

showed the highest sap-stain infestation of $95 \%$. This ascertains the efficacy of NSo fumigation at minimal concentrations for wood protection.

The findings were in conformity with the results reported by Tewari (1992). Michael and Sharma (2006) also reported the toxicity of neem seed oil as a fumigant.

No infestation was observed on treated $T$. grandis specimens at all test concentrations
(Table 3) (Plate 5). Whereas, in SYP control specimens exhibited $25 \%$ surface infestation while $T_{1}, T_{2}$ and $T_{3}$ treatments of NSo reduced it significantly $(\mathrm{p} \leq 0.05)$, exhibiting only 4 , 1 and $0 \%$ infestations respectively (Plate 6). It is interesting to note that $T$. grandis control specimens were not infested either by mould or sap-stain. Its natural resistance may be attributed to the extractives, as described above. While, 
Table 3 Infestation (\%) (approx.) on Tectona grandis and southern yellow pine (SYP) blocks by Alternaria alternata and mould

\begin{tabular}{ccccc}
\hline \multirow{2}{*}{ Treatment } & \multicolumn{4}{c}{ Infestation $(\%)$ on total surface } \\
\cline { 2 - 5 } & Tectona grandis & Grading & SYP & Grading \\
\hline $\mathrm{C}_{1}$ & 0 & 0 & 25 & 2 \\
& & & $(\mathrm{SE}=0.89)$ & \\
$\mathrm{T}_{1}$ & 0 & 0 & 4 & 1 \\
$\mathrm{~T}_{2}$ & 0 & 0 & $(\mathrm{SE}=0.33)$ & 1 \\
$\mathrm{~T}_{3}$ & 0 & 0 & $(\mathrm{SE}=0.09)$ & \\
\hline
\end{tabular}

$\mathrm{SE}=$ standard error

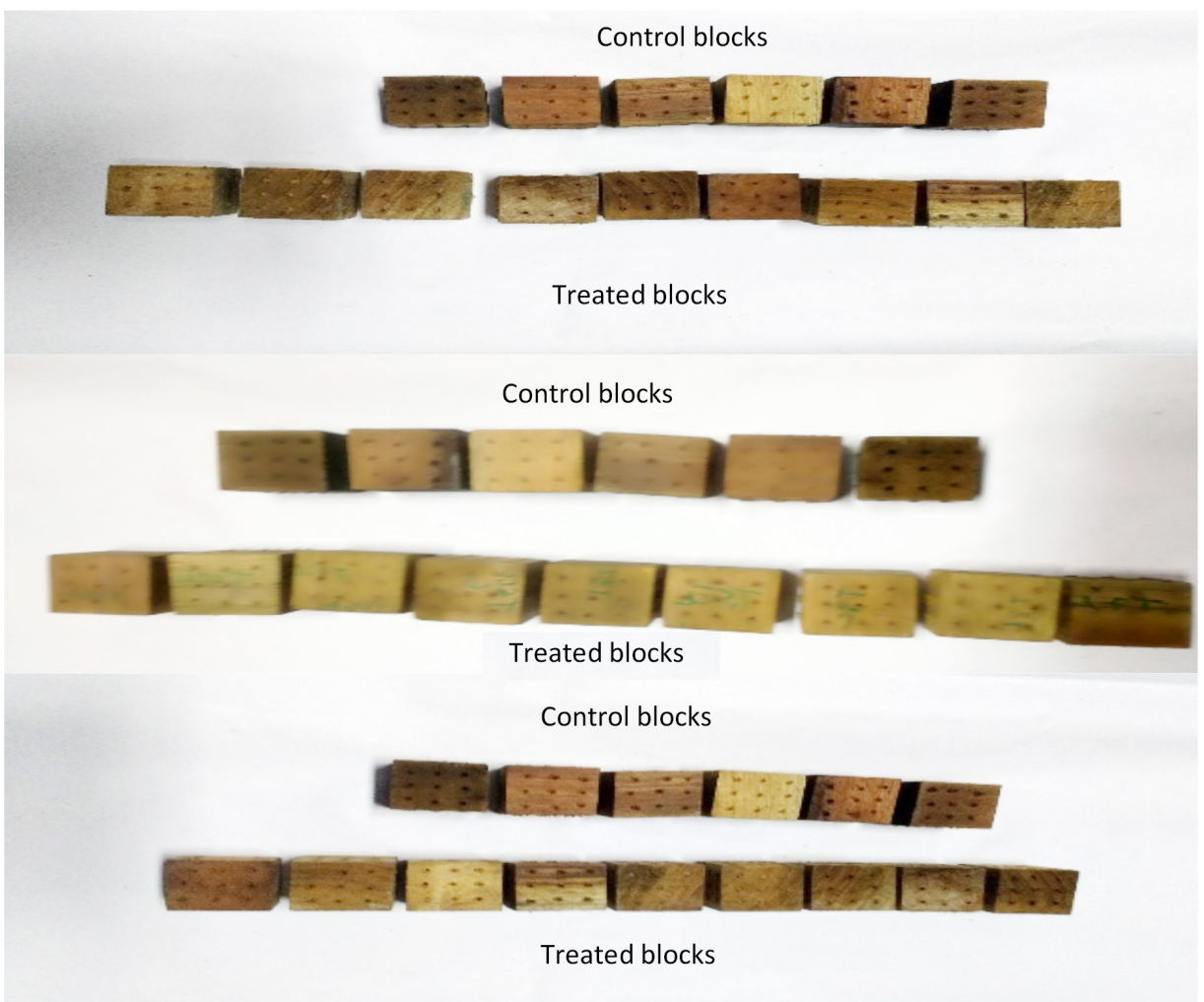

Plate 5 Infestation on fumigated blocks of Teak fumigated with 1, 2 and $3 \mathrm{ml}$ of Neem seed oil (control blocks and treated blocks)

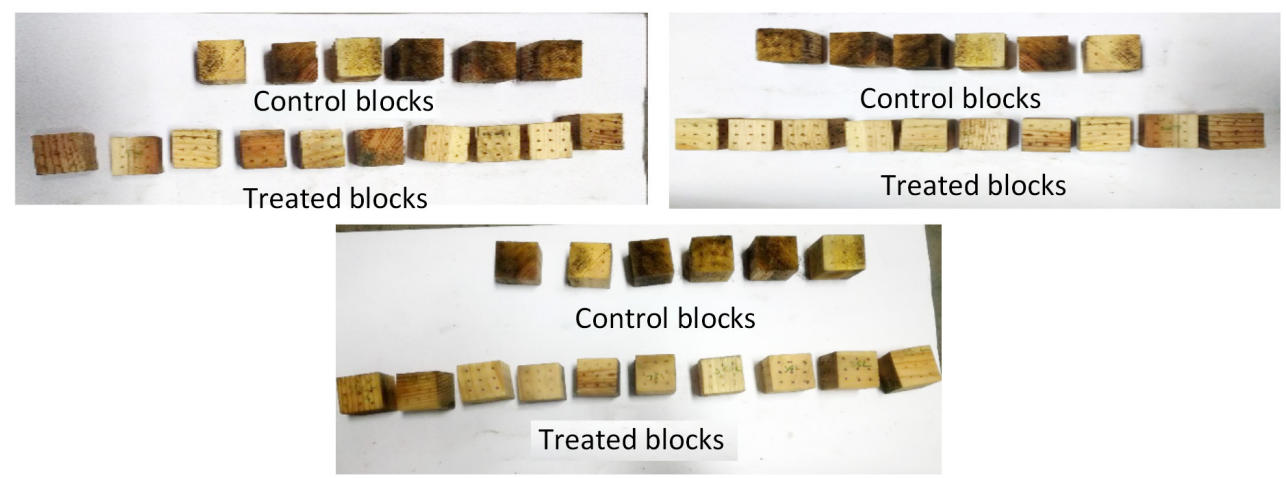

Plate 6 Infestation on fumigated blocks of southern yellow pine fumigated with 1, 2 and 3 ml Neem seed oil 


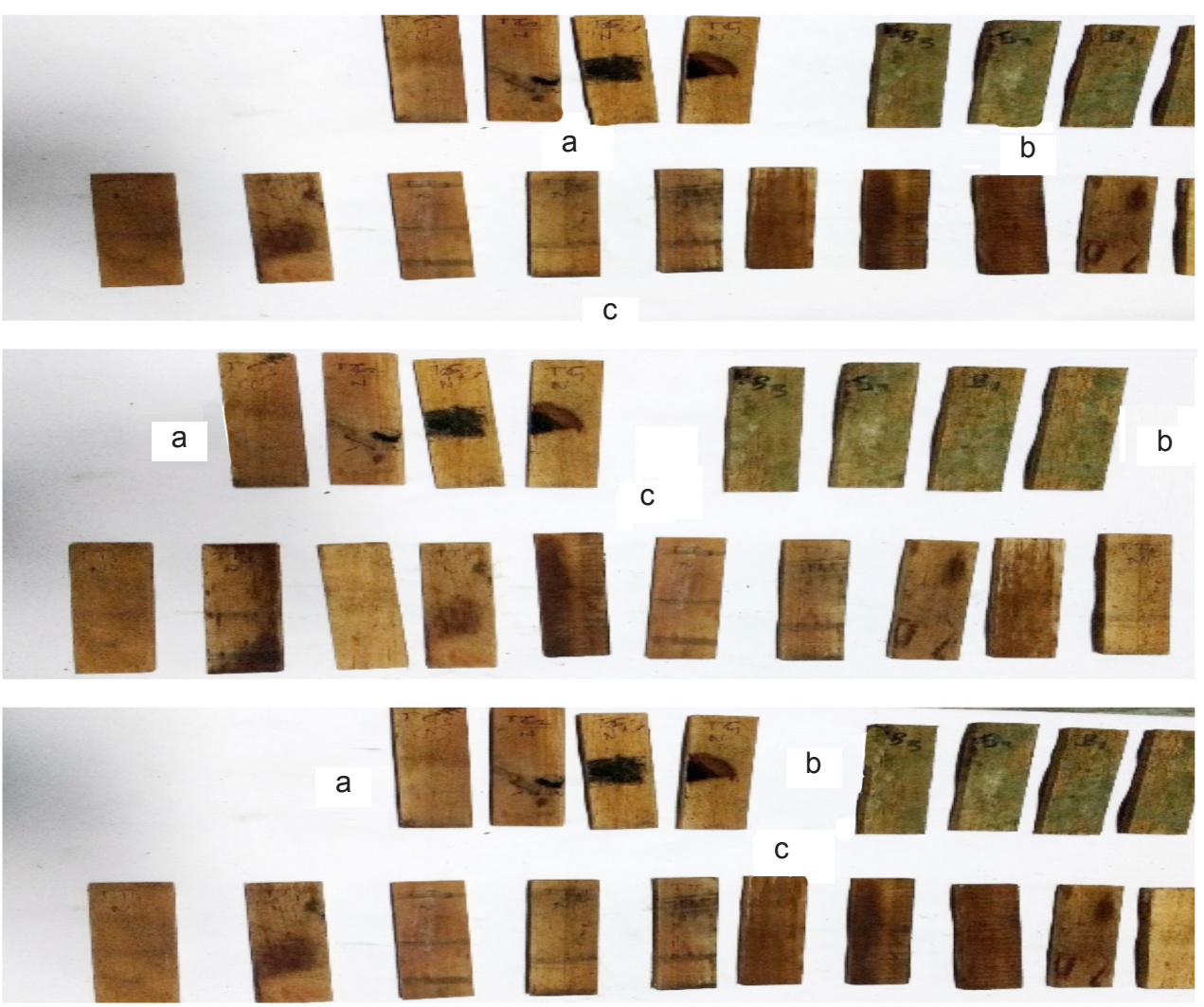

Plate 7 Infestation on blocks of Teak fumigated with 1, 2 and $3 \mathrm{ml}$ of Neem seed oil, a) control veneers of Teak, b) control veneer of Bombax ceiba, c) treated specimen of Teak

SYP had less natural resistance as compared to T. grandis, exhibiting $25 \%$ infestation on control specimens. It was further noted that NSo showed good potential for resistance, and is eco-friendly in nature. Hence, further trials on pilot scale should be carried out to explore and tap the resource for wood protection.

Table 4 exhibits infestation of sap-stain and mould on veneer specimens. The SYP showed infestations of 6,2 and $0 \%$ respectively for the three treatments $T_{1}, T_{2}$ and $T_{3}$. Veneers of $T$. grandis receiving $T_{1}, T_{2}$ and $T_{3}$ had no visual infestation, while control specimens of SYP showed fungal infestation of $15 \%$. Control of T. grandis showed only $10 \%$ infestation. It is interesting to report that the highly perishable species, susceptible to attack of stains and fungi, B. ceiba $\mathrm{C}_{2}$, exhibited infestation of $90 \%$. This revealed that both the test species, $T$. grandis and SYP, showed inherent resistance and natural durability in control specimens. This may be due to the presence of certain chemicals like tectoquinones in T. grandis (Rudman and Gay 1961, Rudman et al. 1958), while the chemical constituent responsible for wood protection in SYP need to be studied further.
It was observed that the fungi infestation grading in blocks and veneer of the same species was not comparable, the probable reason being the surface area available for infestation.

The NSo concentrations used for the study was highly effective for inhibiting growth of test fungi and mould as shown in Petri plates and test blocks, hence, has potential for exploitation in field trials.

\section{CONGLUSION}

The NSo is of natural origin and available in adequate quantity, however, it was not studied for its efficacy against sap-stain and moulds in wood protection through fumigation in laboratory trails. In the present study it was inferred that NSo is effective in protection of SYP and T. grandis wood against sap-stain and mould fungi in laboratory conditions, as the infestations in wood specimens of both species reduced significantly after the treatments. The use of NSo as a fumigant may be safer for the environment as well as for the workers than synthetic compounds, and hence stands a chance to gain more acceptability amongst 
Table 4 Infestation (\%) on veneer speimens (Tectona grandis, southern yellow pine (SYP) and Bombax ceiba) by Alternaria alternata and mould

\begin{tabular}{ccccccc}
\hline \multirow{2}{*}{ Treatment } & \multicolumn{5}{c}{ Infestation $(\%)$ on total surface } \\
\cline { 2 - 6 } & Tectona grandis & Grading & SYP & Grading & Bombax ceiba & Grading \\
\hline $\mathrm{C}_{1}$ & $10(\mathrm{SE}=0.45)$ & 1 & $15(\mathrm{SE}=0.56)$ & 1 & - & - \\
$\mathrm{C}_{2}$ & - & - & - & - & $90(\mathrm{SE}=0.84)$ & 5 \\
$\mathrm{~T}_{1}$ & 0 & 0 & $6(\mathrm{SE}=0.40)$ & 1 & - & - \\
$\mathrm{T}_{2}$ & 0 & 0 & $2(\mathrm{SE}=0.30)$ & 1 & - & - \\
$\mathrm{T}_{3}$ & 0 & 0 & 0 & 0 & - & - \\
\hline
\end{tabular}

$\mathrm{SE}=$ standard error

consumers. Pilot scale trails in industry, with the help of fumigation agencies, will provide the opportunity to explore and exploit this resource on a larger scale.

\section{REFERENCES}

ASTM (AMERICAN SOCiety FOR TERTING AND WATERIAls) D4445-09. 2009. Standard Test Method for Fungicide For Controlling Sapstain, Old On Unseasoned Lumber (Laboratory Method). ASTM International, Pennsylvania. DOI: 10.1520/D4445-09A.

Bond EJ. 1984. Manual of Fumigation for Insect Control. FAO Plant Production and Protection Paper No. 54. Food and Agriculture Organization of the United Nations, Rome.

Cartwright KSG \& Findlay WPK. 1948. Decay of Timber and Its Prevention. Forest Products Research Laboratory, Department of Scientific and Industrial Research, London.

Chaudhary S, Kanwar RK, Sehgal A, Cahill DM, Barrow CJ, SeHgal R \& Kanwar JR. 2017. Progress on Azadirachta indica based biopesticides in replacing synthetic toxic pesticides. Frontiers in Plant Science 8: 610. Doi: 10.3389/fpls.2017.00610.

CPM (Commission on Phytosanitary). 2008. Replacement or Reduction of the Use of Methyl Bromide as a Phytosanitary Measure. IPPC Recommendation. Report of the Third Session of the Commission on Phytosanitary Measures, Appendix 6. International Plant Protection Conventiion (IPPC), Food and Agriculture Organisation (FAO), Rome.

DATAR VV. 1995. Antifungal activity of neem (Azadirachta indica) leaves against some phytopathogenic fungi. Pp 49-51 in Mariappan V (ed) Neem for the Management of Crop Diseases. Associated Publishing Co., New Delhi.

DhyAni S. 2008. Development of wood preservative from neem leaves and seeds. PhD thesis. Indian Council of Forest Research and Education, Forest Research Institute, Dehradun, India.

Djibril D, Mamadou F, Gérard V, Geuye MC, Oumar S. \& LuC R. 2015. Physicalcharacteristics, chemical composition and distribution of constituents of the neem seeds (Azadirachta indica A. Juss). Research Journal of Chemical Sciences 5: 52-58.
Dua P, Santosh S, Pant K \& Satya N. 2016. Eco-friendly preservation of bamboo species: traditional to modern techniques. Bioresourcees 11: 10604-10624.

Findlay WPK \& Pettifor CB. 1939. The effect of sap-stain on the properties of timber: effect of sap-stain on the modulus of elasticity of scots pine sapwood. Forestry: An International Journal of Forest Research 13: 146-147.

IS (INDIAN STANDARDS) 11215. 1991. Moisture Content of Timber and Timber Products-Methods for Determination. Bureau of Indian Standards, Manak Bhawan, New Delhi.

IS (Indian Standards) 4833. 1993. Methods for Field Testing of Preservatives in Wood. Bureau of Indian Standards, Manak Bhawan, New Delhi, India.

IS (INDIAn STANDARDS) 401. 2001. Preservation of Timber-Code of Practice. Bureau of Indian Standards, Manak Bhawan, New Delhi, India.

KAPSE NK. 1996. Formulation of biofungicidal preparation to control fungal decay of stored bamboos with particular emphasis on Trichoderma species. PhD thesis. Indian Council of Forestry Research and Education (ICFRE), Dehradun.

Krameash. 2015. Beyond 2015: alternatives for methyl bromide fumigation for management of stored product and quarantine pests. http://agropedia. iitk.ac.in/content/beyond-2015-alternatives-methylbromide-fumigation-management-stored-productand-quarantine-pests.

Kumar S \& Dev I. 1993. Wood Preservation in India. Indian Council of Forestry Research and Education (ICFRE), Dehradun.

Mahmoud DA, Hassanein NM, Youssef KA \& Abou-Zeid MA. 2011. Antifungal activity of different neem leaf extracts and the nimonol against some important human pathogens. Brazilian Journal of Microbiol 42: 1007-1016.

McDonald AG \& Donaldson LA. 2001. Encyclopedia of Materials: Science and Technology. Elsevier, Amsterdam.

Meier E. 2019. Pine wood: an overall guide. The wood database. https://www.wood-database.com/woodarticles/pine-wood-an-overall-guide/.

Michael RS \& SHARma RK. 2006. Fumigant toxicity of neem formulation against Sitophilus oryzae and Rhyzopertha dominica. Journal of Agriculture Technology 2: 1-16.

Monro HAU. 1980. Manual of Fumigation for Insect Control. Oxford publishing Co., Oxford.

Morrell JJ \& Corden ME. 1968. Controlling wood deterioration with fumigants: a review. Forest Products Journal 36: 26-34. 
Morrell JJ \& Zabel RA. 1992. Wood Microbiology: Decay and Its Prevention. Academy Press, San Diego.

Morrell JJ, Love CS \& Freitag CM. 2002. Preventing discoloration of unseasoned hem-fir and douglas-fir lumber with selected fungicide formulations. Forest Products Journal 52: 53.

Mondal D \& Mondal T. 2012. A Review on efficacy of Azadirachta indica A. Juss based biopesticides: an Indian perspective. Research Journal of Recent Sciences 1: 94-99.

Pant H. 2010. Efficacy of few potential chemicals and neem oil for wood protection through fumigation. $\mathrm{PhD}$ thesis. Indian Council of Forest Research and Education (ICFRE), Forest Research Institute, Dehradun.

Pant H \& TRIPAThi S. 2010. Fungal decay resistance of wood fumigated with Chloropyriphos. Interenational Biodeterioration and Biodegradation, 64: 665-669.

Pant H \& Tripathi S. 2011. Potential of neem seed oil in wood protection through fumigation. Journal of Ecofriendly Agriculture 6: 84-89.

RAO RV. 1990. Natural decay resistance of neem wood. Journal of Indian Academy of Wood Science 21: 19-21.

Rudman P, Da Costa EWB, Gay FJ \& Wetherly AH. 1958. Relationship of tectoquinone to durability in Tectona grandis. Nature 181: 721-722.

RUdman P \& GAY FJ. 1961. The causes natural durability in timber part VI. Measurement of anti-termite properties of anthraquinones from Tectona grandis L.f. by rapid semi-micro method. Holzforschung 15:117-120.
Scheffer TC \& Lindgren RM. 1940. Stains of Sapwood and Sapwood Products and Their Control. Technical Bulletin. United States Department of Agriculture, Washington.

Shrivastava S \& Saxena AK. 2017. Wood is Good: But, is India Doing Enough to Meet its Present and Future Needs? Centre for Science and Environment, New Delhi.

STAHL E. 1969. Thin Layer Chromatography. A Laboratory Handbook, $2^{\text {nd }}$ Edition. Springer Verlag, BerlinHeidelberg, New York.

Syofuna A, Banana AY \& Nakabonge G. 2012. Efficiency of natural wood extractives as wood preservatives against termite attack. Maderas. Ciencia y Tecnología 14: 155-163.

SCbefFer TC. 1958. Control of Decay and Sap Stain in Logs and Green Lumber. Products Laboratory, Forest Service US Department of Agriculture, Washington.

Sundararaj R, Shanbhag RR, Nagaveni HC \& Vijayalakshm G. 2015. Natural durability of timbers under Indian environmental conditions-an overview. International Biodeterioration and Biodegradation 103: 196-214.

Tewari DN. 1992. Monograph of Neem. International Book Distributor, Dehradun.

Thwaites JM, Farrell RL, Duncan SM et al. 2005. Survey of potential sapstain fungi on Pinusradiata in New Zealand. New Zealand Journal of Botany 43: 653-663.

Vogel I. 1978. A Text Book of Practical Organic Chemistry Including Qualitative Analyis. Longmans, Green and Co., London, New York, Toronto.

Wedge DE, Galindo JCG \& Macias FA. 2000. Fungicidal activity of natural and synthetic sesquiterpene lactone analogs. Phytochemistry 53: 747-757. 